\section{Old laws stop drugs being used in valuable new ways}

SIR — I strongly agree with Curtis Chong and David Sullivan's Commentary calling for the development of new uses for existing medications (Nature 448, 645-646; 2007). However, I don't believe that establishing a database of all the drugs known to clinical medicine would be sufficient to spur fresh applications of drugs in the developed world. The stumbling block here is not information gathering but economics and patent laws.

Frederick Goodwin, former director of the US National Institute of Mental Health, recently commented that lithium remains underused in high-risk patients - despite strong evidence that, unlike most other psychiatric medications, it significantly lowers the risk of suicide in people with manic-depressive illness (see R. J. Baldessarini et al. Bipolar Disord. 8, 625-639; 2006). Similarly, although folic acid has been shown to increase the efficacy of antipsychotic medications in certain patients (see J. Levine et al. Biol. Psychiat. 60, 265-269; 2006), a psychiatrist at a recent meeting told me that he could not persuade his colleagues to prescribe this comparatively harmless vitamin.

Such difficulties stem from the failure of intellectual property laws to assign sufficient value to 'use' patents, involving new uses for old medications. In effect, a discovery of immense human value - preventing suicide - is assigned a negligible economic value that fails to motivate the pharmaceutical industry to develop the drug. The antiquated laws governing new uses for existing medications need to be reformed if lifesaving discoveries are to be exploited.

\section{S. Paul Berger}

Department of Veterans Affairs Medical Center, 3710 SW US Veterans Hospital Road,

Mail Code R\&D 64, Portland, Oregon 97239, USA

\section{Transparent frogs show potential of natural world}

SIR - Your News in Brief story 'See-through frog offers inside information' (Nature 449, $521 ; 2007)$ reporting the creation of a transparent frog (Rana japonica) by M. Sumida and collaborators highlights an important achievement. But there are natural transparent tetrapods, which are not the result of genetic manipulation. The roughly 150 species of anurans commonly known as glass frogs (family Centrolenidae) show a high variation in degree of transparency, not only in their skin but also in the different peritonea covering their organs (see picture).

These natural 'see-through' frogs allow the observation in vivo of internal organs, which

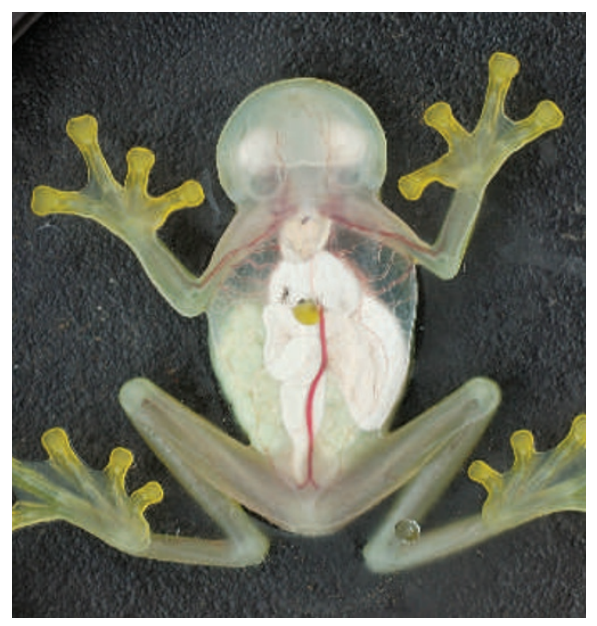

Naturally transparent: ventral view of a gravid female glass frog Hyalinobatrachium bergeri; snout-vent length $23 \mathrm{~mm}$.

has potential for useful applications in the biomedical sciences. Further, although the transparent mutants of $R$. japonica are difficult to generate (only one out of 16 is transparent) and have very low fitness, glass frogs represent a highly diverse group widespread throughout the American tropics.

We know very little about these arboreal transparent frogs. But their potential use in biomedical research highlights the importance that should be attached to the exploration of biodiversity - as stressed in your 15 March 2007 issue, dedicated to Linnaeus's legacy.

Santiago Castroviejo-Fisher ${ }^{\star}$, Ignacio De la Rivał', Carles Vilà

*Department of Evolutionary Biology, Uppsala University, Norbyvägen 18D, 75236 Uppsala, Sweden

†Museo Nacional de Ciencias Naturales/CSIC, 28006 Madrid, Spain

\section{Mars needs technology designed for sample return}

SIR - In your Q\&A 'Space, science and the bottom line' (Nature 448, 978; 2007), Alan Stern, NASA's associate administrator for science, expresses his determination to make the Mars sample-return programme a reality. On NASA's wish list for decades, the mission would collect and return to Earth samples of martian rocks, soils and atmosphere.

But Stern's goal won't be achieved by assembling rocket propulsion systems from currently proven satellite components, as is customary for planetary spacecraft.

There is no equivalent in the satellite world, nor in the defence industry, for a launch vehicle the size of a person, which is what's needed to return martian samples to Earth affordably. The velocity and acceleration required to lift a vehicle from Mars are twice the values needed to launch from our Moon. Indeed, this technical challenge is so daunting that it's impossible to tell whether a Mars sample-return mission will work without actually building and testing miniature launch-vehicle technology. Such technology won't result from commercial market forces, as do other advances that benefit spacecraft, such as computer chips, lightweight imagers and even satellite propulsion.

Stern should aim to bring about the Mars sample-return mission by building and testing technology designed for the purpose, not by revisiting mission design options, which may only extend 35 years of hopes to 40 or 50 .

\section{John Whitehead}

Physical Sciences Directorate, Lawrence Livermore National Laboratory, L-072

PO Box 808, Livermore, California 94551, USA

\section{Call for scientists to speak up for human rights}

SIR - As chair of the American Physical Society's Committee on International Freedom of Scientists, I wish to express my alarm about the kafkaesque situation confronting the Russian biologist Oleg Mediannikov, reported in your News story 'Russian scientists see red over clampdown' (Nature 449, 122-123; 2007).

The American Physical Society is the biggest organization of physicists in the United States, with a large international membership. The society is independent of any government, and its international freedom committee is responsible for monitoring the human rights of scientists throughout the world, including the United States, and assisting those in need. In the past couple of years our efforts have been partially focused on Russia, where several scientists collaborating with foreign researchers have been intimidated and prosecuted.

As well as Mediannikov, we are actively assisting Valentin Danilov, Oscar Kaibyshev, Igor Sutyagin and Oleg Korobeinichev. We are committed to defending our colleagues at risk and we will continue to raise our voices whenever scholars encounter a prohibition on travelling, publishing or pursuing research. We call upon scientific humanrights organizations to join us to protest at restrictions, by any government, on the free exchange of ideas, be it by denying visas or barring scholars from attending conferences or taking academic positions.

Juan C. Gallardo

Brookhaven National Laboratory, Upton, New York 11973, USA

Contributions to this page may be sent to correspondence@nature.com.Wewelcome comments on publishing issues at Nautilus (http://blogs.nature.com/nautilus). 